\title{
Managing Organizational Open Innovation Capability in a Knowledge-Intensive Business Environment
}

\author{
Yuliia Lazarenko, ${ }^{1, *}$, and Olga Garafonova $^{1}$, Vyktoriia Marhasova $^{2}$, Nataliia Tkalenko ${ }^{3}$, \\ Svetlana Grigashkina ${ }^{4}$ \\ ${ }^{1}$ Vadym Hetman Kyiv National Economic University, Management Department, 03057, 54/1 Pr. \\ Peremogy, Kyiv, Ukraine \\ ${ }^{2}$ Chernihiv National University of Technology, Accounting, Tax and Audit Department, 14035 \\ Chernihiv, Ukraine \\ ${ }^{3}$ Chernihiv National University of Technology, Public Administration and Business Management \\ Department, 14035 Chernihiv, Ukraine \\ ${ }^{4}$ T. F. Gorbachev Kuzbass State Technical University, 650000, 28 Vesennyaya St., \\ Kemerovo, Russia
}

\begin{abstract}
The paper is aimed to develop a theoretical framework for investigating the main determinants of an organizational open innovation capability and provide a conceptual basis for identifying the core areas which are of importance for effectively managing the implementation of open innovation practices within business organizations. Based on a literature review of research on managerial practices for open innovation collaboration, a definition of a company's open innovation capability is proposed which places special emphasis on the interrelationship among the strategic components of a business organization's environment and its dynamic knowledge management capacities. As a result of the study, the integrated model of the organizational open innovation capability is presented that can be used for defining strategic priorities and managerial guidelines for achieving open innovation success. From a practical perspective, companies can apply the proposed conceptual model to review and adjust their organizational open innovation capability on a continuous basis in order to improve innovation performance in the challenging knowledge-intensive business environment.
\end{abstract}

\section{Introduction}

In today's complex business environment where knowledge and information flows have become decisive elements in achieving and maintaining competitiveness, open innovation activities and collaborative projects are playing an increasingly important role in enhancing a firm's ability to innovate successfully and have the potential to enable companies to operate more efficiently in dynamic business conditions by producing outstanding innovative outcomes. Modern organizations, especially small and medium-sized enterprises, often found it difficult under changing economic and technological conditions to pursue major innovations as well as implement substantial product and process improvements on an ongoing basis through their own efforts, mainly due to the lack of knowledge, experience, financial, technical and technological resources or appropriate skills and functional competencies. In this context, open innovation tools are seen to offer

* Corresponding author: yuliia.lazarenko@kneu.ua 
modern business organizations collective benefits and considerable opportunities beyond those of a single company, and hence increase their market adaptability.

According to the open innovation paradigm, organizations can acquire the necessary resources, knowledge, skills, and experience from external sources and share internal resources to provide product or service developments [1-4]. Given the growing scientific interest in issues related to open innovation practices, the advantages, benefits and various positive aspects of open innovation activities are widely discussed in modern studies in the area of innovation management. However, the question of what organizational capabilities and managerial competencies from a company's viewpoint are required to facilitate successful interaction with external partners within an open innovation ecosystem remains contentious.

This research focuses on developing a comprehensive model of an organizational open innovation capability and is intended to identify its significant dimensions which should be primarily taken into account from a managerial decision-making perspective in order to collaborate effectively and efficiently in open innovation projects.

\section{Materials and Methods}

The open innovation concept is considered as a contemporary trend in innovation management, however, from a practical perspective, it can be criticized for being too prescriptive [5]. During the last decades extensive studies aimed at understanding the open innovation activities were conducted, but still the practical prescriptions and appropriate managerial guidelines for the enhancing the open innovation capability of organizations are overly generalized and need to be more clearly specified. In this regard, a comprehensive and systematic conceptual framework, guiding managers towards building and developing organizational open innovation capability in a knowledge-intensive business environment should be devised.

Many of the prior research studies related to managing organizational innovation capabilities have focused primarily on the internal activities, core competencies of a company as well as the resources it possesses as the key mechanisms driving innovation performance. However, business organizations which operate under the existing market principles and rapidly changing economic conditions for the most part are not able to innovate successfully alone and maintain on a continuous basis appropriate internal capabilities in all potentially relevant areas. This has given rise to the recognition of the importance of monitoring the external sources of innovation and seeking necessary capabilities beyond the traditional boundaries of the firm. In this vein, the practice of open innovation which can be considered as a modern trend in managing the innovation process, assumes that specific innovation capabilities of a company can emerge from both internal and external sources. Networks and alliances of customers, suppliers, partners, competitors and other actors of the innovation ecosystem can be regarded in this context as potential sources of innovation. Open innovation collaboration offers opportunities to expand access to the required resources, experience and competencies from the firm's business environment that can be used in order to improve its innovation performance and enhance its efficiency, effectiveness and competitive capacities.

This paper presents a theoretical framework for investigating the main determinants of an organizational open innovation capability and provides a basis for defining the core areas which are of critical importance for effectively managing the process of open innovation implementation within organizations. Based on an extensive review of the open innovation management literature, a conceptual definition of a company's open innovation capability is developed which places special emphasis on the dynamic knowledge management capacities. The paper is structured as follows: first, a descriptive overview of 
the theoretical aspects of the capability-based approach to open innovation is provided. Then, based on a review of the existing open innovation management literature and thematic research, a definition of an open innovation capability is proposed. As a result of the study, through the integrated approach a comprehensive model of the organizational open innovation capability is presented that can be used for determining long-term strategic priorities related to managerial practices for open innovation collaboration.

\section{Results and Discussion}

In reviewing the theoretical aspects of the capability-based approach to open innovation, it should be specified that a capability generally implies a set of resources and knowledge of their usage [6]. Innovation capability refers in this regard to a firm's ability to take the risk and generate new ideas which build innovativeness [7]. From a theoretical viewpoint, many authors consider the concept of innovation capability as a specific aspect of a company's innovation performance that could be measured quantitatively through a set of indicators of innovation related achievements. However, it should be noted that such an approach has some limitations: although comprehensive quantitative assessments can provide relevant information on the innovation performance of the firm, they might not fully capture the level of its organizational innovation capabilities. In that respect, we share the opinion that the concept of innovation capability is not a performance indicator but rather should be considered as an integrative characteristic of a company that reflects its preparedness and willingness to devise and implement innovative strategies through the organizational resources, skills, and functional competencies.

Applying the integrated approach to the organizational innovation capability, it should be taken into account that innovation is widely recognized as a complex multifaceted concept and it is not sufficient from a company's perspective to focus on a single dimension of an innovation capability to set up an efficient innovation process. Innovation capability in this consideration can be determined in a generalized way as the result of the interrelationship among the strategic components of a business organization's environment which are crucial to foster enabling conditions for innovation-oriented activities, e.g. resources, knowledge, experience, managerial approaches and techniques, skills, qualifications and competencies, as well as connections with other actors participating in the innovation ecosystem.

The capability perspective originates from the resource-based view of the firm, so the main emphasis in the discussion on dynamic capabilities has been on how companies integrate, reconfigure, and transfer their own or controllable internal resources as well as renew functional competencies [6]. The term "organizational capability" with regard to innovation activities underlines the importance of appropriate strategic management tools and techniques in developing and improving organizational skills, resources and competencies in order to adjust to changing factors of a business environment and be able of responding flexibly to challenges that hinder innovation. Although when it comes to open innovation practice, the ability to integrate efforts of the different types of innovation stakeholders and exploit external resources within the innovation process is an increasingly crucial factor for the sustainable innovation activities which could lead to commercially successful products and services.

In a knowledge-intensive business environment, where comprehensive knowledge cocreation and sharing mechanisms become essential to innovation development and competitiveness, a high-level open innovation capability can be achieved when there is a balanced position between knowledge exploration and exploitation that is accompanied by the total process of scanning, organizing and transferring knowledge-based experience in a company. With regard to knowledge management, following the approach proposed by $B$. 
Lawson and D. Samson (2001) two main types of organizational capabilities can be distinguished: functional capabilities which allow a company to expand its internal knowledge base, and integrative capabilities that relate to a firm's ability to gain the required knowledge from external sources and combine different resources and competencies developed in various departments of organization in order to stimulate innovation [8]. According to J. Cohen and D.A. Levinthal (1990) to make full use of the potential of external knowledge sources in a productive manner, business organizations need to absorb and integrate the knowledge they acquire [9]. The company's ability to absorb knowledge gained through participation in external innovation networks is therefore of the crucial importance of effective open innovation practice.

In accordance with the approach proposed by P. Skarzynski and R. Gibson (2008), the innovation capability of a company can be considered as an integrative concept which includes such elements as an organizational culture and corporate values, leadership competencies, structures and systems of an organization as well as processes and tools required to promote innovation [10]. In a similar vein, by A. Suominen and J. Jussila (2009) was developed an integrated model of innovation capability which comprises both the main organizational contextual features and individual components [11]. The proposed model encompasses the interrelated domains relevant to the innovation performance: organizational climate and corporate culture, including corporate values, organizational structure and leadership style, organization processes, tools and mechanisms that enable to maintain and promote the generation of new ideas and implementation of innovation as well as human resource skills and competencies, e.g., professional and technical expertise, change- and risk orientation, conceptual thinking, flexibility, initiative, etc.

In this regard reference should be made to the comprehensive model of an organizational innovation capability developed by M. Momeni, S.N. Nielsen and M.H. Kafash (2015). According to this approach, the innovation capability is determined by other internal capabilities of the company which can be classified into three main dimensions: structural capability, personnel capability, and operational capability [12]. The researchers believe, that the organizational innovation capability is strongly dependent on the technological and support capacities of a company, the employees' individual knowledge and experience, the creativity of human resources as well as a set of other interrelated capacities related to the internal processes of organization (e.g., managerial, cultural, communicative, etc.).

Following the conceptualization related to the important factors affecting implementation of the open innovation practices proposed by O. Gassmann, P. Sandmeier and C.H. Wecht (2004), it could be suggested that main managerial dimensions of an organizational open innovation capability include innovation strategy (e.g., corporate strategy, learning strategy, mission, vision, strategic goals and objectives), structure (e.g., organizational structures and communication), process (e.g., technology processes, decision-making processes, internal collaboration tools, appropriate mechanisms for managing innovation projects), corporate culture (e.g., organizational climate, strategic corporate values, management style, leadership and support with regard to open innovation, risk-taking attitude and organizational readiness for change), and linkages or networks (e.g., attitude towards collaborative practices, ability to maintain and manage innovation network relationships, etc.).

The analysis of existing viewpoints suggests the conclusion that organizational open innovation capability is determined by the interrelationship among the strategic components of a business organization's environment and can be defined as a company's integrative ability to dynamically manage its knowledge base by using inbound as well as outbound information flows, experience, skills and functional competencies, which provides the basis for a subsequent transformation of existing knowledge and ideas into new products, 
services, processes, structures or decisions for the economic benefits for both the company and its innovation stakeholders.

With reference to the summarized literature on the basis of the above-mentioned areas that are identified as being particularly relevant for providing the open innovation activities in the knowledge-intensive business environment, an integrated model of the organizational open innovation capability can be presented (Figure 1), which is developed by the authors adapting $[1 ; 4 ; 6-18]$.

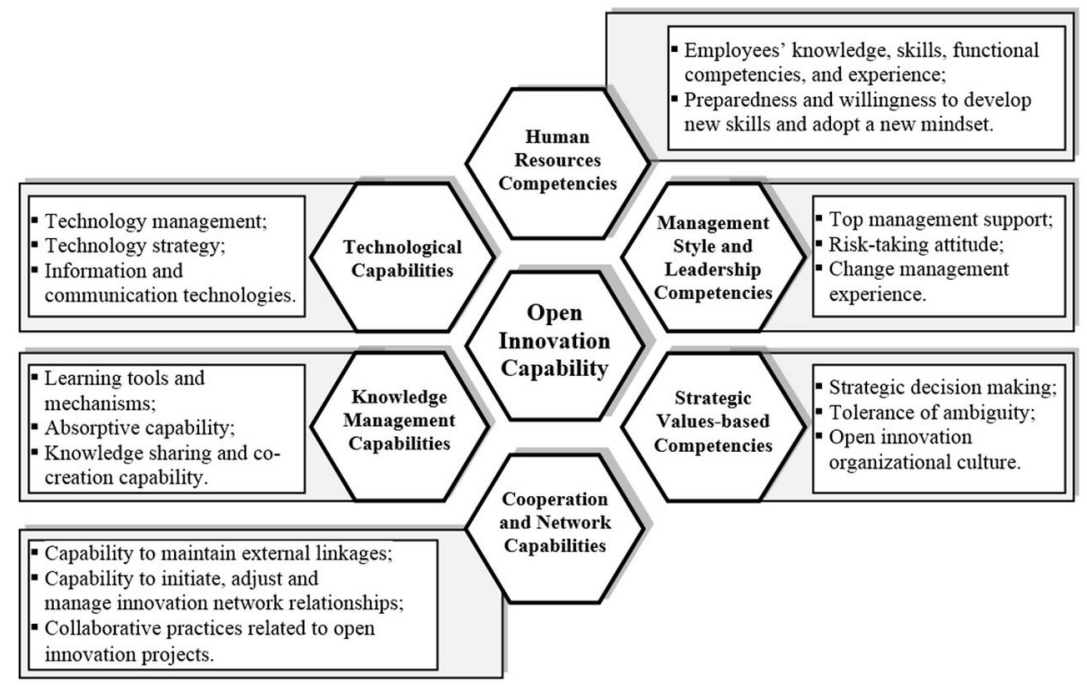

Fig. 1. An integrated model of the organizational open innovation capability

The proposed holistic model assumes that the organizational open innovation capability is composed of interrelated and mutually reinforcing components which include the innovation-oriented practices, processes, and competencies within the company, and is aimed at building a theoretical basis for the identification of the key managerial areas which most affect successful open innovation practice. The major elements making up an open innovation capability of an organization can be broadly grouped in six thematic domains: management style and leadership competencies, strategic values-based competencies, human resources competencies, technological capabilities, knowledge management capabilities as well as cooperation and network capabilities of a company that have been identified as being of particular relevance with regard to managing open innovation projects.

Both in the literature on the innovation management and in thematic research a lot of attention is paid to identifying the essential prerequisites for the effective and efficient implementation of open innovation practice. Given that each organization has its own characteristics and contextual features, there are varying opinions and perspectives in dealing with the categorization of core elements that determine innovation capabilities and the extent of their influence in terms of adopting open innovation approach. However, it should be noted that many authors point to the importance of an appropriate climate and supportive corporate culture within the organization as crucial enablers for the implementation and maintenance of innovation practices in the firm [13]. In this paper an open innovation-oriented culture is recognized as an element that is closely interrelated to the strategic values-based competencies. The essential aspects of an organizational culture conducive to the promotion of open innovation include tolerance of ambiguity and uncertainty, risk-taking attitude, willingness to change and change management experience 
in a company, as well as an efficient system of communication that facilitates information and knowledge exchange.

Another important component of the open innovation capability is knowledgemanagement capacities relating to the creation, exploration, and exploitation of organizational knowledge, which refer to accumulated skills and expertise [14]. In the open innovation framework it is assumed that activities relevant to the knowledge management practices can take place not just within the organizations, but also beyond their boundaries $[1 ; 18]$. The combination of internal and external knowledge flows in the innovation process and, accordingly, an efficient knowledge flow management is in this regard of critical importance. And it is necessary to point out that from the practical perspective maintenance of internal and external knowledge is related to organizational processes and provides a basis for the effective knowledge transfer through which the successful knowledge exchange, sharing and co-creation practices can be implemented. In accordance with a dynamic capabilities approach [14;18], firms should develop, renew and rearrange their knowledge management capacities over time to benefit from the open innovation collaboration.

The open innovation capability relates directly with specific managerial competencies such as developing a clear innovation strategy, planning an appropriate organizational structure, adopting relevant decision-making mechanisms, as well as the use of innovation networks and other collaborative practices and maintain external linkages related to innovation-oriented activities. Thus, the open innovation capability should be seen as a result of the interaction of interrelated organizational factors, competencies, and capacities and it needs to be emphasized that appropriate coordination among these elements, as well as top management support with regard to open innovation collaboration can be considered as necessary facilities for development of organizational open innovation capability which should be taken into account and carried out by the management of a company [15].

\section{Conclusions}

Based on the findings of the study, it is possible to outline some practical aspects of managing the organizational open innovation capability in today's knowledge-intensive business environment:

- it is crucial for innovation-oriented companies to review, adjust, transform and reconfigure on a continuous basis their organizational open innovation capability to fit fast-changing business conditions;

- in order to ensure efficient and effective collaboration and coordination in the open innovation projects, it is critical for the companies to integrate their internal and external knowledge flows as well as share knowledge-based experience and maintain a balanced position between knowledge exploration and exploitation;

- successful reconfiguration of the open innovation capability's determinants requires organizational changes which may be achieved by means of appropriate managerial tools, structural and contextual intra-firm mechanisms, the systems, structures, processes, corporate values and expectations that shape organizational behavior and determine the staff attitude towards risk and uncertainty, tolerance of ambiguity and willingness to adopt a new mindset which is necessary for an open innovation;

- to innovate efficiently and improve the open innovation capability of the firm the creation of new ideas and knowledge is essential. Thus, companies have to put particular emphasis on the complementary character of internal and external knowledge and information flows to enhance successful open innovation collaboration, so, both external and internal learning mechanisms are important to the firm's open innovation capability building. Leading innovators make a point of linking organizational learning 
mechanisms as well as goal-driven knowledge exploration and exploitation strategies to products, processes, technologies and innovation capabilities.

To conclude, the essential goals of managing organizational open innovation capability are to create new resource combinations to respond to changing business conditions, and consequently to sense and seize opportunities through a reconfiguration of the main determinants of the company's open innovation capability. It is necessary to emphasize that the traditional dimensions of an organizational innovation capability, such as technological and human resources capacities are not sufficient for successful open innovation implementation. According to the research findings, the additional open innovation capability's determinants are significant for modern enterprises, such as cooperation and network capabilities, management style and leadership competencies, and strategic valuesbased competencies. Building upon this study, the next issues are to investigate what steps can be undertaken from a managerial viewpoint in order to enhance the above-mentioned dimensions of the organizational open innovation capability.

\section{References}

1. H. Chesbrough. Open Business Models: How to Thrive in the New Innovation Landscape (Boston, MA: Harvard Business School Press, 2006)

2. H. Chesbrough, W. Vanhaverbeke, J. West. Open Innovation: Researching a New Paradigm (Oxford: Oxford University Press, 2006)

3. O. Gassmann, E. Enkel. Towards a Theory of Open Innovation: Three Core Process Archetypes (The Proceedings of the R\&D Management conference, Lisbon, Portugal, 2004)

4. O. Gassmann, P. Sandmeier, C.H. Wecht. IO New Management, 73, 31 (2004)

5. J. Tidd, J. Bessant. Managing Innovation: Integrating Technological, Market and Organizational Change (Wiley, New Jersey, John Wiley \& Sons, 2018)

6. K. Möller, S. Svahn. Marketing Theory, 3:2, 201 (2003)

7. R.J. Calantone, S.T. Cavusgil, Y. Zhao. Industrial Marketing Management, 31:6, 515 (2002)

8. B. Lawson, D. Samson. International Journal of Innovation Management, 5:3, 377 (2001)

9. J. Cohen, D.A. Levinthal. Administrative Science Quarterly, 35:1, 554 (1990)

10. P. Skarzynski, R. Gibson. Innovation to the Core: a Blueprint for Transforming the Way Your Company Innovates (Cambridge, MA: Boston, Mass., Harvard Business School Press, 2008)

11. A. Suominen, J. Jussila. Organizational Innovation Capability (Building Blocks of Agile Innovation, Book Surge Publishing, Charleston, SC, 2009)

12. M. Momeni, S.B. Nielsen, M.H. Kafash. Determination of Innovation Capability of Organizations: Qualitative Meta Synthesis and Delphi Method (The Proceedings of RESER, Innovative Services in the 21st Century, 2015)

13. K. Szczepańska-Woszczyna. Forum Scientiae Oeconomia, 2:3, 27 (2014)

14. C.E. Helfat, S. Finkelstein, W. Mitchell, M. Peteraf, H. Singh, D. Teece, S.G. Winter. Dynamic Capabilities: Understanding Strategic Change in Organizations (Malden, MA: Blackwell Publishing, 2007)

15. G. Colarelli O'Connor. Journal of Product Innovation Management, 25, 313 (2008) 
16. A.H. Lassen, A. Jacobsen, S.B. Poulsen, S. Wandahl. Emerging Capabilities of Open Innovation in Networks (The Proceedings of the World Conference on Mass Customization, Personalization, and Co-Creation: Bridging Mass Customization \& Open Innovation, Raleigh, North Carolina, Lulu Press, Inc., 2011)

17. R. Adams, A. Alexander, C. Öberg. Innovation Management Capabilities for Start-ups and Spin-offs: a Literature Review (The Proceedings of the IMP Conference, Bordeaux, France, 2014)

18. U. Lichtenthaler, E. Lichtenthaler. Journal of Management Studies, 46:8, 1315 (2009) 